\title{
Three-Dimensionally Structured Polypyrrole-Coated Setaria Viridis Spike Composites for Efficient Solar Steam Generation
}

\author{
Zhanjun Xie, ${ }^{\dagger},+$ Jintao Zhu, ${ }^{*},{ }^{\dagger}$ and Lianbin Zhang ${ }^{*}, \dagger,+$ \\ †Key Laboratory of Material Chemistry for Energy Conversion and Storage of Ministry of Education, School \\ of Chemistry and Chemical Engineering, Huazhong University of Science and Technology (HUST), Wuhan \\ 430074, China. \\ ${ }^{\ddagger}$ Shenzhen Huazhong University of Science and Technology Research Institute, Shenzhen 51800, China \\ ${ }^{*}$ Corresponding Author. Email: zhanglianbin@hust.edu.cn (L. Z.); jtzhu@mail.hust.edu.cn (J. Z.)
}




\section{Supporting Figures:}

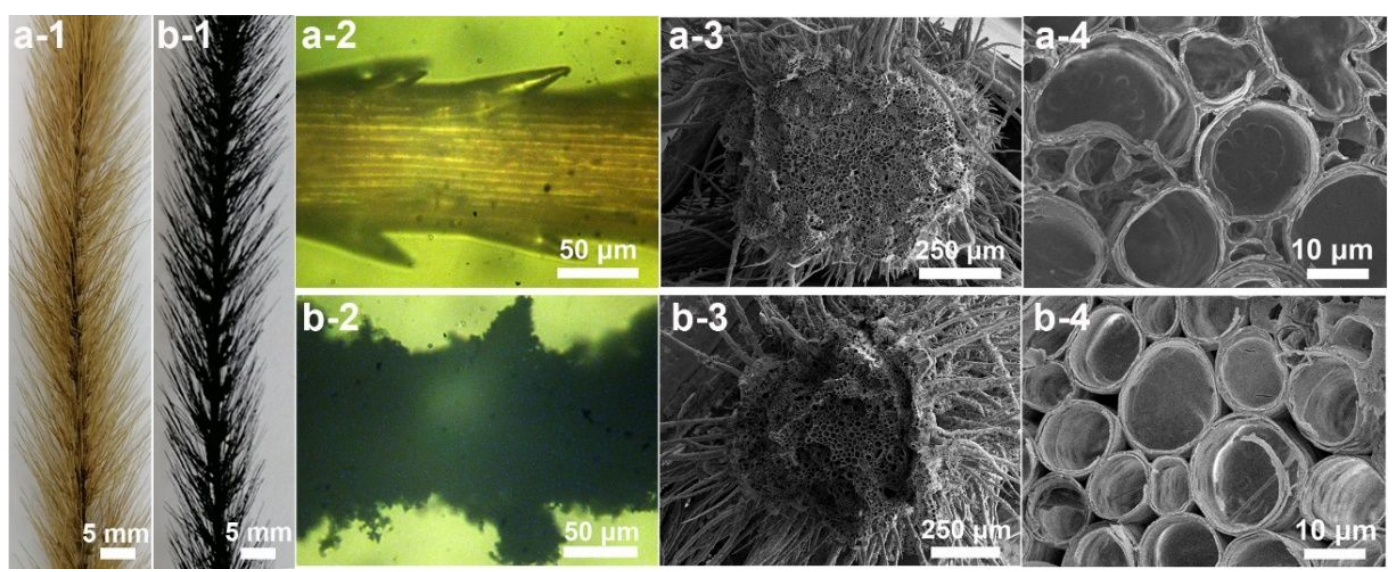

Figure S1. Optical images of (a-1) Setaria viridis spike and (b-1) PPy-coated Setaria viridis spike. Optical microscope pictures of (a-2) bristle of Setaria viridis spike and (b-2) bristle of PPy-coated Setaria viridis spike. SEM images of the cross-section of Setaria viridis spike (a-3) and cross-section at higher magnification (a-4). Cross-section of PPy-coated Setaria viridis spike (b-3) and cross-section at higher magnification (b-4).

a

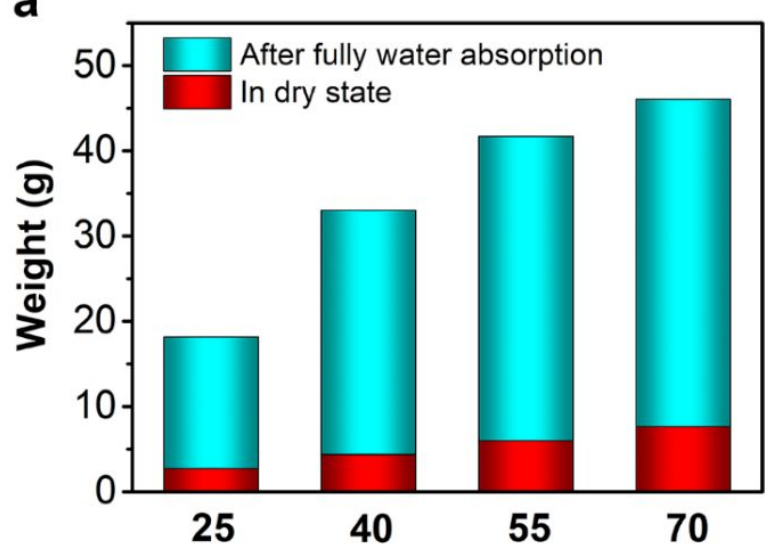

b

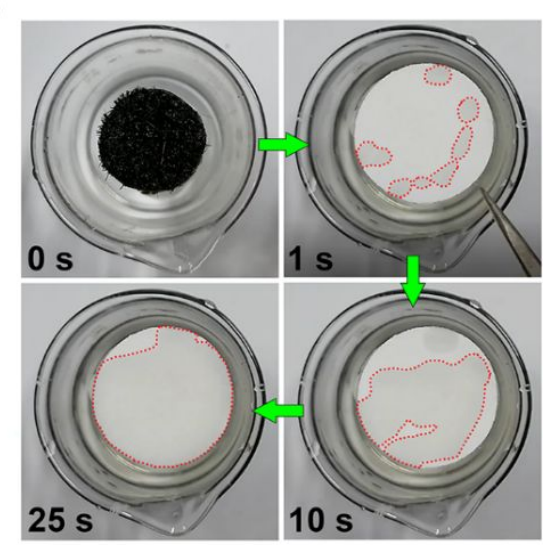

Figure S2. (a) The mass of PPy-coated Setaria viridis spike in dry state and after water absorption. (b) Photographs showing that within $25 \mathrm{~s}$, filter paper placed on top of the PSSE-N55-H4 can be wetted by water. Outlines indicated the wetted area.
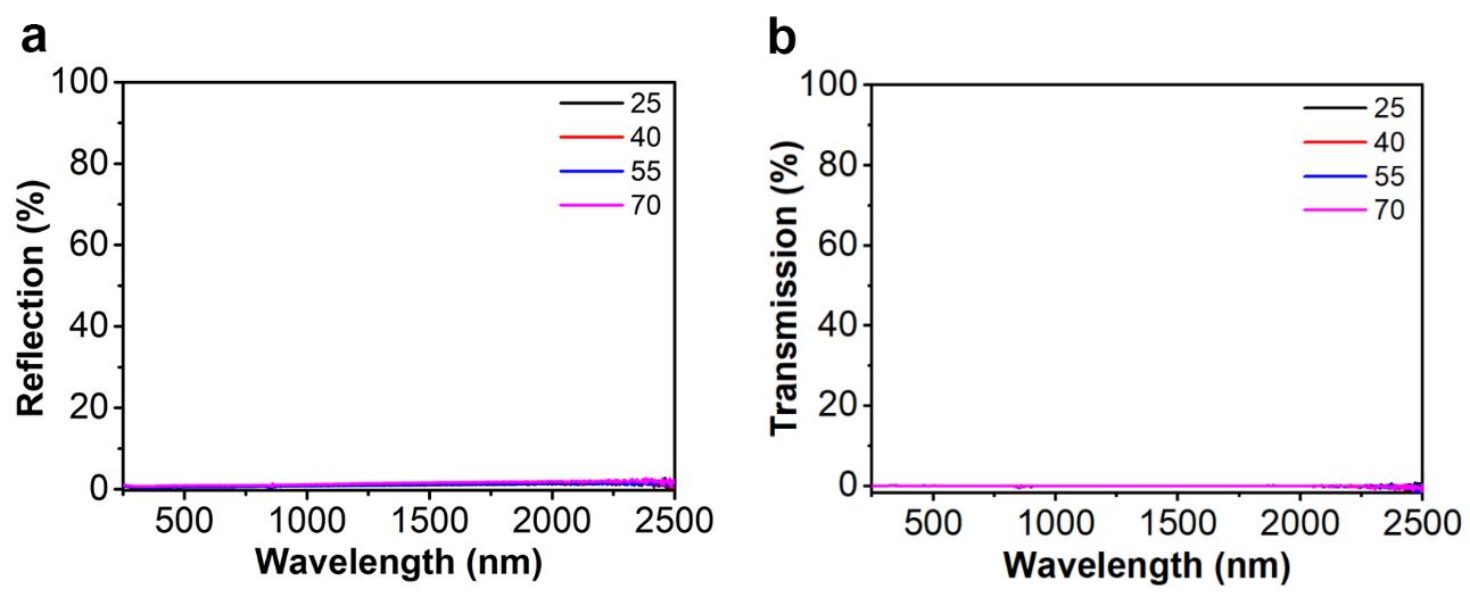

Figure S3. UV-Vis-NIR (a) reflection and (b) transmission spectra of four PPy-coated Setaria viridis spike 
samples.
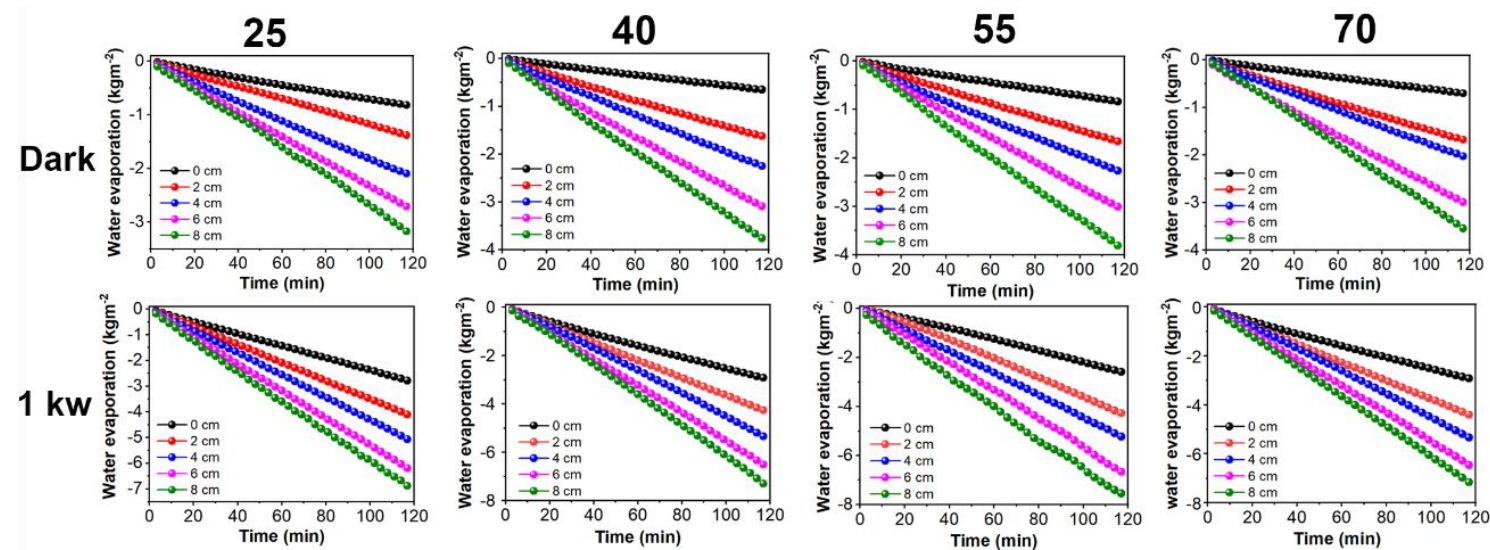

Figure S4. Water evaporation performances with PSSEs with different spike numbers and different heights under the dark condition and one sun illumination.

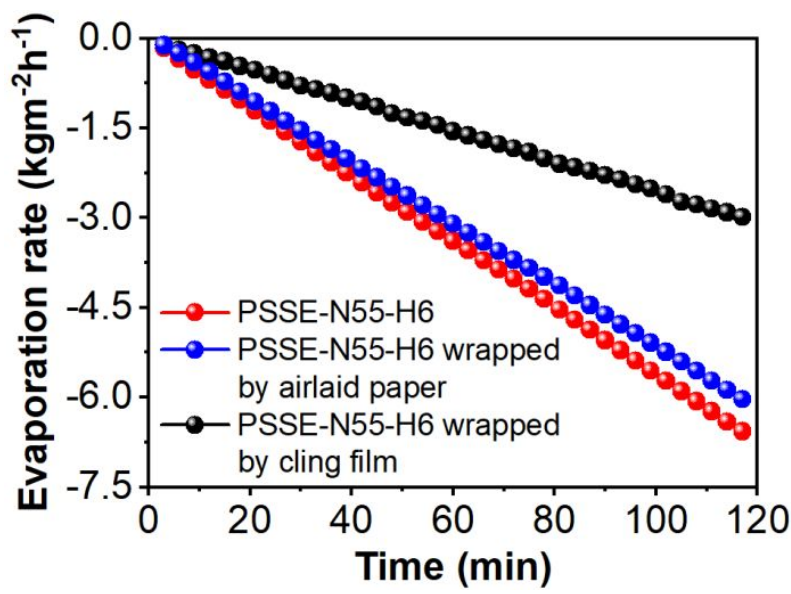

Figure S5. Water evaporation performances with PSSE-N55-H6, PSSE-N55-H6 wrapped by airlaid paper, PSSE-N55-H6 wrapped by cling film under one sun illumination.

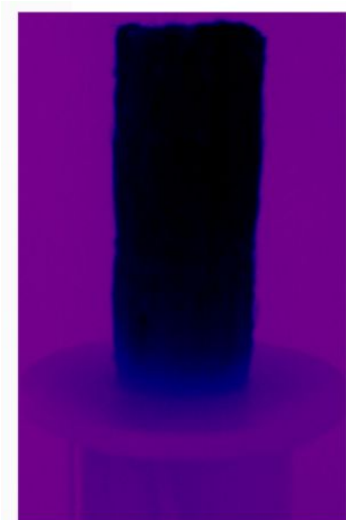

$0 \min$

PSSE-N55-H6

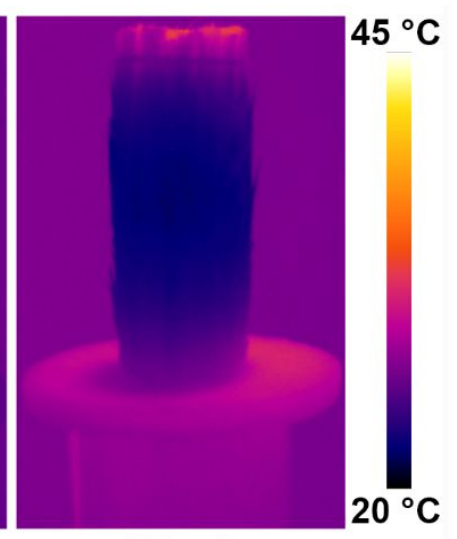

$120 \mathrm{~min}$

PSSE-N55-H6

Figure S6. Thermal images of PSSE-N55-H6 under 0 min and $2 \mathrm{~h}$ solar light irradiation. 


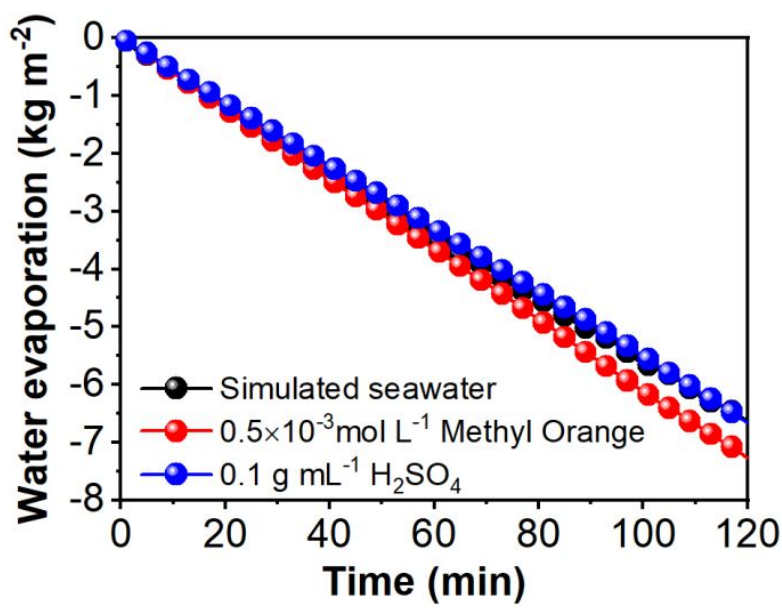

Figure S7. Evaporation of simulated seawater, dye (Methyl Orange)-contaminated water, the sulfuric acid aqueous solution with the PSSE under one sun illumination.

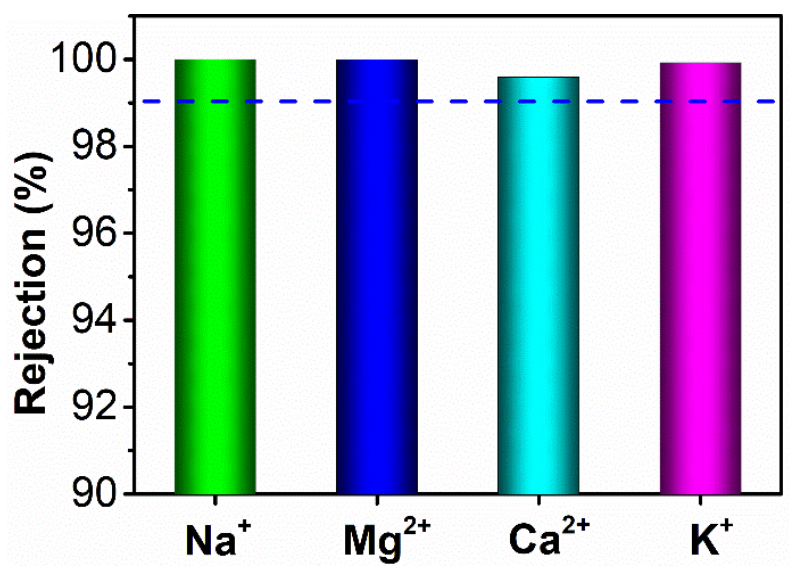

Figure S8. Ion rejection percentages.

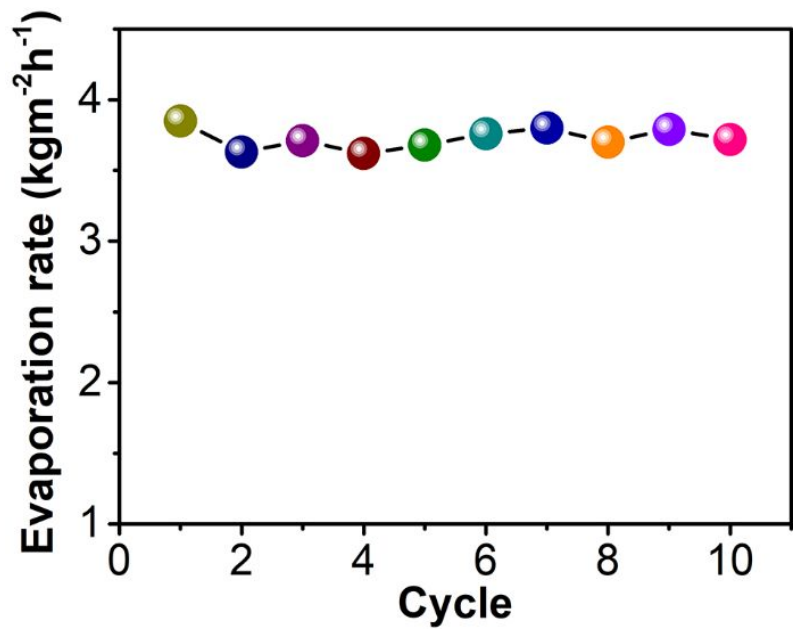

Figure S9. Water evaporation rates with the PSSE-N55-H6 over 10 cycles under one sun illumination. Each cycle lasts for 2 hours.

\section{Supporting Tables:}


Table S1 Comparison of surface temperature after $2 \mathrm{~h}$ solar light irradiation.

\begin{tabular}{|c|c|c|c|c|c|c|}
\hline \multirow{2}{*}{$T_{\mathbf{e}_{\text {mp }}} \mathbf{H}$} & \multicolumn{5}{|c|}{ Height above the water surface (H) } \\
\cline { 2 - 7 } & $\mathbf{0}$ & $\mathbf{2}$ & $\mathbf{4}$ & $\mathbf{6}$ & $\mathbf{8}$ \\
\hline $\mathbf{N}$ & 40.6 & 38.8 & 37.8 & 37.3 & 38.0 \\
\hline $\begin{array}{c}\text { Number } \\
\text { of PPy- } \\
\text { coated }\end{array}$ & $\mathbf{2 5}$ & 40.4 & 37.6 & 36.9 & 36.3 & 37.4 \\
\cline { 2 - 7 } $\begin{array}{c}\text { Setaria } \\
\text { Viridis } \\
\text { spike } \\
\text { (N) }\end{array}$ & $\mathbf{5 5}$ & 40.3 & 36.8 & 36.0 & 35.6 & 36.7 \\
\cline { 2 - 7 } & $\mathbf{7 0}$ & 40.7 & 38.6 & 37.6 & 36.9 & 37.3 \\
\hline
\end{tabular}

Table S2 Comparison of solar steam generation under one sun illumination.

\begin{tabular}{|c|c|c|c|c|}
\hline Materials & Dimension & $\begin{array}{l}\text { Evaporation rate } \\
\qquad \mathrm{kg} \mathrm{m}^{-2} \mathbf{h}^{-1} \\
\end{array}$ & Ref & Year \\
\hline $\begin{array}{l}\text { polypyrrole-coated Setaria viridis spike } \\
\text { composites (This work) }\end{array}$ & $3 \mathrm{D}$ & 3.72 & This work & 2020 \\
\hline $\begin{array}{c}\text { vertically aligned activated carbone juncus } \\
\text { effusus }\end{array}$ & $3 \mathrm{D}$ & 2.23 & S28 & 2020 \\
\hline activated carbon-cotton fabric & $3 \mathrm{D}$ & 1.95 & S27 & 2020 \\
\hline nanodiamonds paint filter paper & $3 \mathrm{D}$ & 1.32 & S26 & 2020 \\
\hline $\begin{array}{l}\text { ten-stage thermally-localized multistage solar } \\
\text { still prototype }\end{array}$ & $3 \mathrm{D}$ & 5.78 & S25 & 2020 \\
\hline polypyrrole decorated maize straws & $3 \mathrm{D}$ & 3.00 & S24 & 2020 \\
\hline RGO-bamboo paper & $3 \mathrm{D}$ & 2.94 & S23 & 2020 \\
\hline original filter paper@PPy & $3 \mathrm{D}$ & 2.30 & S22 & 2020 \\
\hline $\begin{array}{l}\text { polydopamine coated nickel-cobalt bimetal } \\
\text { nanosheets }\end{array}$ & $3 \mathrm{D}$ & 2.42 & $\mathrm{~S} 21$ & 2020 \\
\hline Carbondot@cellulose paper & $3 \mathrm{D}$ & 2.93 & S20 & 2020 \\
\hline Wood-tannic acid-Fe ${ }^{3+}$ & $3 \mathrm{D}$ & 1.85 & S19 & 2020 \\
\hline $\begin{array}{c}\text { Ag nanoparticles@ polydopamine decorated } \\
\text { on Wooden Flower }\end{array}$ & $3 \mathrm{D}$ & 2.08 & S18 & 2020 \\
\hline reduced graphene oxide-wood derived aerogel & $3 \mathrm{D}$ & 1.35 & S17 & 2020 \\
\hline $\begin{array}{l}\text { air-laid paper wrapped acrylonitrile-styrene- } \\
\text { acrylate }\end{array}$ & $3 \mathrm{D}$ & 1.71 & S16 & 2020 \\
\hline hydrophilic carbon felt & $3 \mathrm{D}$ & 1.56 & S16 & 2019 \\
\hline $\begin{array}{c}\text { multiwalled carbon nanotube and poly } \\
\text { acrylamide-radial aerogel }\end{array}$ & $3 \mathrm{D}$ & 2.00 & S14 & 2019 \\
\hline reduced graphene oxide-agarose-cotton aerogel & $3 \mathrm{D}$ & 4.00 & S13 & 2019 \\
\hline black nylon fibers@ planar polyvinyl chloride & $3 \mathrm{D}$ & 2.09 & S12 & 2019 \\
\hline hydrophilic Polyaniline-cotton fabric & $3 \mathrm{D}$ & 1.94 & S11 & 2019 \\
\hline
\end{tabular}




\begin{tabular}{|c|c|c|c|c|}
\hline origami PPy-paper composite & 3D & 2.12 & $\mathrm{~S} 10$ & 2019 \\
\hline copper disc@ copper disc & $3 \mathrm{D}$ & 2.20 & S9 & 2019 \\
\hline polypyrrole coated PVDF membrane & $3 \mathrm{D}$ & 1.70 & S8 & 2018 \\
\hline $\begin{array}{c}\mathrm{CuFeMnO}_{4} @ \text { quartz glass fibrous filter } \\
\text { membrane }\end{array}$ & $3 \mathrm{D}$ & 2.04 & S7 & 2018 \\
\hline $\mathrm{MoS}_{2} / \mathrm{C} @$ Polyurethane & $3 \mathrm{D}$ & 1.95 & S6 & 2018 \\
\hline carbon-coated paper & $3 \mathrm{D}$ & 2.20 & S5 & 2018 \\
\hline carbonblack@Cellulose/cotton & $3 \mathrm{D}$ & 1.62 & S4 & 2018 \\
\hline GO/CNTs@ porous cellulose filterpaper & $3 \mathrm{D}$ & 1.59 & S3 & 2018 \\
\hline $\begin{array}{l}\text { highly vertically ordered pillar array of } \\
\text { graphene framework }\end{array}$ & $3 \mathrm{D}$ & 2.10 & S2 & 2018 \\
\hline carbonized mushrooms & $3 \mathrm{D}$ & 1.48 & S1 & 2017 \\
\hline
\end{tabular}

\section{Supporting Notes:}

Note S1. The water evaporation rate $(v)$ can be calculated by Equation S1:

$$
v=\frac{\Delta m}{A_{1} \times t}
$$

Where $v$ is the evaporation rate $\left(\mathrm{kg} \mathrm{m}^{-2} \mathrm{~h}^{-1}\right), \Delta m$ is the mass change of water $(\mathrm{kg})$ at steady state, $A_{l}$ is the projection area of the evaporator $\left(\mathrm{m}^{2}\right)$, and $t$ is the evaporation time $(\mathrm{h})$.

Note S2. The solar-to-evaporation energy conversion efficiency ( $\eta$ ) can be calculated from the total energy

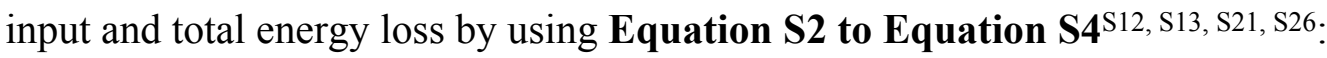

$$
\eta=\frac{Q_{\text {total }}-Q_{\text {loss }}}{Q_{\text {total }}}
$$

where $Q_{\text {total }}$ is the total energy input in our solar steam generation system including the energy input from simulated solar light and surrounding environment and $Q_{\text {loss }}$ is the total energy loss.

$$
\begin{gathered}
Q_{\text {total }}=A_{1} q_{\text {solar }}+A_{2} \varepsilon \sigma\left(T_{\text {environment }}^{4}-T_{\text {low }}^{4}\right)+A_{2} h\left(T_{\text {environment }}-T_{\text {low }}\right) \\
Q_{\text {loss }}=A_{1} R q_{\text {solar }}+A_{1} \varepsilon \sigma\left(T_{\text {top }}^{4}-T_{\text {environment }}^{4}\right)+A_{1} h\left(T_{\text {top }}-T_{\text {environment }}\right)+A_{3} \varepsilon \sigma\left(T_{\text {high }}^{4}-T_{\text {environment }}^{4}\right)+A_{3} h\left(T_{\text {high }}-T_{\text {environment }}\right)+A_{4} q_{\text {water }}
\end{gathered}
$$

where $A_{1}$ is the projection area of the evaporator to the water surface, $R$ is the reflectivity of the absorber $(\sim 0.8 \%), q_{\text {solar }}$ is the solar flux $\left(1 \mathrm{~kW} \mathrm{~m}^{-2}\right), A_{2}$ is the projection area (to the normal direction) of the sidewall of the evaporator where the surface temperature of the evaporator is lower than the environment temperature, 
$A_{3}$ is the projection area (to the normal direction) of the sidewall of the evaporator where the surface temperature of the evaporator is higher than the environment temperature, $q_{\text {water }}$ is the heat flux from the evaporator to the underlying water including conduction and radiation, $A_{4}$ is the contact area between the evaporator and the water in the heat flux process, $\varepsilon$ is the emmittance of the surface (i.e., 1), $\sigma$ is the StefanBoltzmann constant (i.e., $5.67 \times 10^{-8} \mathrm{~W} \mathrm{~m}^{-2} \mathrm{~K}^{-4}$ ), $T_{\text {top }}$ is the surface temperature at the top of the evaporator, $T_{\text {low }}$ is the surface temperature of the sidwall of the evaporator which is lower than the environment temperature, $T_{\text {high }}$ is the surface temperature of the sidewall of the evaporator which is higher than the enviroonment temperature, $T_{\text {environment }}$ is the environment temperature, and $h$ is the convection heat transfer coefficient (5-10 $\left.\mathrm{W} \mathrm{m}^{-2} \mathrm{~K}^{-1}\right)$. Considering that the PSSE was inserted into the water, the energy loss to the underlying water was simplified as the heat conduction loss to the water. The cold evaporation on the sidewall of PSSE makes the temperature of the sidewall of the PSSE lower than that of the environment, therefore we took the area with a high temperature in the center part of PSSE (about $1 \mathrm{~cm}$ in diameter) as the contact area for heat conduction calculation. Given that the thermal conductivity of water is about $0.62 \mathrm{~W} \mathrm{~m}^{-1} \mathrm{~K}^{-1}$, combining with the contact area of $7.85 \times 10^{-5} \mathrm{~m}^{2}$, the energy loss to the underlying water is estimated to be $6.08 \times 10^{-3} \mathrm{~W}$. The solar-to-evaporation energy conversion efficiency using PSSE-N55-H6 was estimated to be $\sim 92.1 \%$.

\section{Supplementary References}

(S1) Xu, N.; Hu, X.; Xu, W.; Li, X.; Zhou, L.; Zhu, S.; Zhu, J. Mushrooms as Efficient Solar Steam-Generation Devices. Adv. Mater. 2017, 29, 1606762.

(S2) Zhang, P.; Liao, Q.; Yao, Q.; Cheng, H.; Huang, Y.; Yang, C.; Jiang, L.; Qu, L. Three-Dimensional Water Evaporation on A Macroporous Vertically Aligned Graphene Pillar Array under One Sun. J. Mater. Chem. A 2018, 6, 15303-15309.

(S3) Hong, S.; Shi, Y.; Li, R.; Zhang, C.; Jin, Y.; Wang, P. Nature-Inspired, 3D Origami Solar Steam Generator toward Near Full Utilization of Solar Energy. ACS Appl. Mater. Interfaces 2018, 10, 28517-28524. 
(S4) Li, X.; Li, J.; Lu, J.; Xu, N.; Chen, C.; Min, X.; Zhu, B.; Li, H.; Zhou, L.; Zhu, S.; Zhang, T.; Zhu, J. Enhancement of Interfacial Solar Vapor Generation by Environmental Energy. Joule 2018, 2, 1331-1338.

(S5) Song, H.; Liu, Y.; Liu, Z.; Singer, M. H.; Li, C.; Cheney, A. R.; Ji, D.; Zhou, L.; Zhang, N.; Zeng, X.; Bei, Z.; Yu, Z.; Jiang, S.; Gan, Q. Cold Vapor Generation beyond the Input Solar Energy Limit. Adv. Sci. 2018, $5,1800222$.

(S6) Li, W.; Tekell, M. C.; Huang, Y.; Bertelsmann, K.; Lau, M.; Fan, D. Synergistic High-Rate Solar Steaming and Mercury Removal with MoS2/C@Polyurethane Composite Sponges. Adv. Energy Mater. 2018, 8,1802108 .

(S7) Shi, Y.; Li, R.; Jin, Y.; Zhuo, S.; Shi, L.; Chang, J.; Hong, S.; Ng, K.-C.; Wang, P. A 3D Photothermal Structure toward Improved Energy Efficiency in Solar Steam Generation. Joule 2018, 2, 1171-1186.

(S8) Wang, Y.; Wang, C.; Song, X.; Huang, M.; Megarajan, S. K.; Shaukat, S. F.; Jiang, H. Improved LightHarvesting and Thermal Management for Efficient Solar-Driven Water Evaporation Using 3D Photothermal Cones. J. Mater. Chem. A 2018, 6, 9874-9881.

(S9) Huang, L.; Jiang, H.; Wang, Y.; Ouyang, Z.; Wang, W.; Yang, B.; Liu, H.; Hu, X. Enhanced Water Yield of Solar Desalination by Thermal Concentrated Multistage Distiller. Desalination 2020, 477, 114260.

(S10) Li, W.; Li, Z.; Bertelsmann, K.; Fan, D. E. Portable Low - Pressure Solar Steaming - Collection Unisystem with Polypyrrole Origamis. Adv. Mater. 2019, 31, 1900720.

(S11) Liu, Z.; Wu, B.; Zhu, B.; Chen, Z.; Zhu, M.; Liu, X. Continuously Producing Watersteam and Concentrated Brine from Seawater by Hanging Photothermal Fabrics under Sunlight. Adv. Funct. Mater. 2019, 29, 1905485.

(S12) Tu, C.; Cai, W.; Chen, X.; Ouyang, X.; Zhang, H.; Zhang, Z. A 3D-Structured Sustainable Solar-Driven Steam Generator Using Super-Black Nylon Flocking Materials. Small 2019, 15, 1902070.

(S13) Wu, X.; Gao, T.; Han, C.; Xu, J.; Owens, G.; Xu, H. A Photothermal Reservoir for Highly Efficient Solar Steam Generation without Bulk Water. Sci. Bull. 2019, 64, 1625-1633.

(S14) Xu, W.; Xing, Y.; Liu, J.; Wu, H.; Cui, Y.; Li, D.; Guo, D.; Li, C.; Liu, A.; Bai, H. Efficient Water Transport and Solar Steam Generation via Radially, Hierarchically Structured Aerogels. ACS Nano 2019, 13, 7930-7938.

(S15) Yu, Z.; Cheng, S.; Li, C.; Li, L.; Yang, J. Highly Efficient Solar Vapor Generator Enabled by a 3D Hierarchical Structure Constructed with Hydrophilic Carbon Felt for Desalination and Wastewater Treatment. ACS Appl. Mater. Interfaces 2019, 11, 32038-32045.

(S16) Cao, N.; Lu, S.; Yao, R.; Liu, C.; Xiong, Q.; Qin, W.; Wu, X. A Self-Regenerating Air-Laid Paper Wrapped ASA 3D Cone-Shaped Janus Evaporator for Efficient and Stable Solar Desalination. Chem. Eng. J. 2020, 397, 125522.

(S17) Chao, W.; Sun, X.; Li, Y.; Cao, G.; Wang, R.; Wang, C.; Ho, S. H. Enhanced Directional Seawater Desalination Using a Structure-Guided Wood Aerogel. ACS Appl. Mater. Interfaces 2020, 12, 22387-22397. (S18) Chen, S.; Sun, Z.; Xiang, W.; Shen, C.; Wang, Z.; Jia, X.; Sun, J.; Liu, C.-J. Plasmonic Wooden Flower for Highly Efficient Solar Vapor Generation. Nano Energy 2020, 76, 104998. 
(S19) He, F.; Han, M.; Zhang, J.; Wang, Z.; Wu, X.; Zhou, Y.; Jiang, L.; Peng, S.; Li, Y. A Simple, Mild and Versatile Method for Preparation of Photothermal Woods toward Highly Efficient Solar Steam Generation. Nano Energy 2020, 71, 104650.

(S20) Wang, Z.; Tu, W.; Zhao, Y.; Wang, H.; Huang, H.; Liu, Y.; Shao, M.; Yao, B.; Kang, Z. Robust CarbonDot-Based Evaporator with An Enlarged Evaporation Area for Efficient Solar Steam Generation. $J$ Mater. Chem. A 2020, 8, 14566-14573.

(S21) Wang, H.; Zhang, C.; Zhang, Z.; Zhou, B.; Shen, J.; Du, A. Artificial Trees Inspired by Monstera for Highly Efficient Solar Steam Generation in Both Normal and Weak Light Environments. Adv. Funct. Mater. 2020. 30, 2005513.

(S22) Shao, B.; Wang, Y.; Wu, X.; Lu, Y.; Yang, X.; Chen, G. Y.; Owens, G.; Xu, H. Stackable NickelCobalt@Polydopamine Nanosheet Based Photothermal Sponges for Fighly Efficient Solar Steam Generation. J. Mater. Chem. A 2020, 8, 11665-11673.

(S23) Wang, Y.; Wu, X.; Shao, B.; Yang, X.; Owens, G.; Xu, H. Boosting Solar Steam Generation by Structure Enhanced Energy Management. Sci. Bull. 2020, 65, 1380-1388.

(S24) Xu, Y.; Tang, C.; Ma, J.; Liu, D.; Qi, D.; You, S.; Cui, F.; Wei, Y.; Wang, W. Low-Tortuosity Water Microchannels Boosting Energy Utilization for High Water Flux Solar Distillation. Environ. Sci. Technol. 2020, 54, 5150-5158.

(S25) Xu, Z.; Zhang, L.; Zhao, L.; Li, B.; Bhatia, B.; Wang, C.; Wilke, K. L.; Song, Y.; Labban, O.; Lienhard, J. H.; Wang, R.; Wang, E. N. Ultrahigh-Efficiency Desalination via A Thermally-Localized Multistage Solar Still. Energy Environ. Sci. 2020, 13, 830-839.

(S26) Zhang, L.; Bai, B.; Hu, N.; Wang, H. Efficient 3D-Interfacial Solar Steam Generation Enabled by Photothermal Nanodiamonds Paint-Coat with Optimized Heat Management. Appl. Therm. Eng. 2020, 171, 115059.

(S27) Zhang, Q.; Hu, R.; Chen, Y.; Xiao, X.; Zhao, G.; Yang, H.; Li, J.; Xu, W.; Wang, X. Banyan-Inspired Hierarchical Evaporators for Efficient Solar Photothermal Conversion. Appl. Energy 2020, 276, 115545.

(S28) Zhang, Q.; Ren, L.; Xiao, X.; Chen, Y.; Xia, L.; Zhao, G.; Yang, H.; Wang, X.; Xu, W. Vertically Aligned Juncus Effusus Fibril Composites for Omnidirectional Solar Evaporation. Carbon 2020, 156, 225 233. 